\title{
Ishikawa Iterates for Logarithmic Function
}

\author{
Rajeshri Rana \\ Asst. Professor \\ Applied Science and Humanities \\ Department \\ G. B. Pant Engg. College, \\ Pauri Garhwal
}

\author{
Yashwant S Chauhan \\ Asst. Professor \\ Computer Science \& Engg. \\ Department \\ G. B. Pant Engg. College, \\ Pauri Garhwal
}

\author{
Ashish Negi \\ Asst. Professor \\ Computer Science \& Engg. \\ Department \\ G. B. Pant Engg. College, \\ Pauri Garhwal
}

\begin{abstract}
In this paper the dynamics of the complex logarithmic function is investigated using the Ishikawa iterates. The fractal images generated from the generalized transformation function $z \rightarrow \log \left(z^{n}+c\right), n \geq 2$ are analyzed.
\end{abstract}

Keywords: : Complex dynamics, Relative Superior Mandelbrot Set, Relative Superior Julia set, Ishikawa Iteration and Midgets.

\section{INTRODUCTION}

The fractals generated from the self-squared function, $z \rightarrow z^{2}+c$ where $z$ and $c$ are complex quantities, have been studied extensively in the literature[2, 8, $9 \& 10]$. A multitude of interesting, intriguing and rich families of fractals are generated by changing the complex function $F(z)$. This paper explores the dynamics of a complex logarithmic function.

In 1918, French mathematician Gaston Julia[12] investigated the iteration process of a complex function intensively and attained a Julia set, which is a landmark in the field of fractal theory. The object Mandelbrot set on the other hand was given by Benoit B. Mandelbrot [13] in 1979. Recently, R. L. Devaney [5], [6] and [7] studied widely the behavior of the exponential function and analyzed the Julia sets under different conditions. We briefly recall the well known result for the family of the quadratic polynomial $Q_{c}(z)=z^{2}+c$. Each map $Q_{c}$ has a single critical point at 0 and so, $Q_{c}$ has a single critical orbit. The fate of this orbit leads to well known fundamental dichotomy for quadratic polynomials:

(1) If $Q_{c}^{n}(0) \rightarrow \infty$, then $J\left(Q_{c}\right)$ is a Cantor set.

(2) But if $Q_{c}^{n}$ does not tends to $\infty$ then, $J\left(Q_{c}\right)$ is a connected set.

The set of parameter values of $\mathrm{c}$ for which the Julia sets of $Q_{c}$ is connected forms the well known Mandelbrot set. The Julia set for parameter $c$ is defined as the boundary between those values of $z_{0}$ that remain bounded after repeated iterations and those that escape to infinity. Julia set is a place where all the chaotic behavior of the complex function occurs. As is well known that Julia sets on the real axis are reflections symmetric while those on the complex plane are rotational symmetric with exception to $c(0,0)$. For a quadratic family, a point at infinity is a super attracting fixed point and so, it is surrounded by an intermediate basin of attraction and if critical orbits tend to infinity, then the critical point must lie in this basin and consequently entire forward orbit lies in this basin.

For the transcendental function, like logarithmic function, Julia set may be defined as closure of the set of the points whose orbits may escape to infinity under the iteration of $Q_{c}$. Equivalently, the Julia set is also closure of the set of the repelling periodic points. These two definitions clearly illustrates the chaotic behavior of Julia sets arbitrarily, close to any point in Julia set are the points whose orbits tends to infinity as well as the other points whose orbits are not only bounded but in fact periodic. For a quadratic family, the only singular value is critical value $c=Q_{c}(0)$, since 0 is the only critical point. Further infinity is the super attracting fixed point for $Q_{c}$. The Mandelbrot set on other hand is the set of values of $c$ for which the orbit of 0 under $Q_{c}$ does not tends to infinity. Equivalently, Mandelbrot set takes those values of $c$, for which Julia sets of, $Q_{c}$ is connected.

\section{PRELIMINEARIES}

The process of generating fractal images from $z \rightarrow \log \left(z^{n}+c\right)$ is similar to the one employed for the selfsquared function[21]. Briefly, this process consists of iterating this function up to $\mathrm{N}$ times. Starting from a value $z_{0}$ we obtain $z_{1,} z_{2}, z_{3}, z_{4}, \cdots$ by applying the transformation $z \rightarrow \log \left(z^{n}+c\right)$.

Definition2.1: Ishikawa Iteration [11]: Let $X$ be a subset of real or complex numbers and $f: X \rightarrow X$ for $x_{0} \in X$, we have the sequences $\left\{x_{n}\right\}$ and $\left\{y_{n}\right\}$ in $\mathrm{X}$ in the following manner:

$$
\begin{aligned}
& y_{n}=s_{n}^{\prime} f\left(x_{n}\right)+\left(1-s_{n}^{\prime}\right) x_{n} \\
& x_{n+1}=s_{n} f\left(y_{n}\right)+\left(1-s_{n}\right) x_{n}
\end{aligned}
$$

where $0 \leq s_{n}^{\prime} \leq 1, \quad 0 \leq s_{n} \leq 1$ and $\quad s_{n}^{\prime} \quad \& \quad s_{n}$ are both convergent to non zero number.

Definition 2.2: The sequences $x_{n}$ and $y_{n}$ constructed above is called Ishikawa sequences of iterations or Relative Superior 
sequences of iterates. We denote it by $R S O\left(x_{0}, s_{n}, s_{n}^{\prime}, t\right)$. Notice that $R S O\left(x_{0}, s_{n}, s_{n}^{\prime}, t\right)$ with $s_{n}^{\prime}=1$ is $S O\left(x_{0}, s_{n}, t\right)$ i.e. Mann's orbit and if we place $s_{n}=s_{n}^{\prime}=1$ then $R S O\left(x_{0}, s_{n}, s_{n}^{\prime}, t\right)$ reduces to $O\left(x_{0}, t\right)$.

We remark that Ishikawa orbit $R S O\left(x_{0}, s_{n}, s_{n}^{\prime}, t\right)$ with $s_{n}^{\prime}=1 / 2$ is relative superior orbit.

Now we define Mandelbrot sets for function with respect to Ishikawa iterates. We call them as Relative Superior Mandelbrot sets [23, 27]

\section{Definition 2.3[23, 27]: Relative Superior Mandelbrot set RSM} for the function of the form $Q_{c}(z)=z^{n}+c$, where $n=1,2,3$, $4 \ldots$ is defined as the collection of $c \in C$ for which the orbit of 0 is bounded i.e.

$R S M=\left\{c \in C: Q_{c}^{k}(0): k=0,1,2 \ldots\right\}$ is bounded.

In functional dynamics, we have existence of two different types of points. Points that leave the interval after a finite number are in stable set of infinity. Points that never leave the interval after any number of iterations have bounded orbits. So, an orbit is bounded if there exists a positive real number, such that the modulus of every point in the orbit is less than this number.

The collection of points that are bounded, i.e. there exists $\mathrm{M}$, such that $\left|Q^{n}(z)\right| \leq M$, for all $n$, is called as a prisoner set while the collection of points that are in the stable set of infinity is called the escape set. Hence, the boundary of the prisoner set is simultaneously the boundary of escape set and that is Julia set for $\mathrm{Q}$.

Definition 2.4[23, 27]]: The set of points RSK whose orbits are bounded under relative superior iteration of the function $Q(z)$ is called Relative Superior Julia sets. Relative Superior Julia set of $\mathrm{Q}$ is boundary of Julia set RSK.

2.1 Generation Process: The basic principle of generating fractals employs the iterative formula: $z_{n+1} \leftarrow f\left(z_{n}\right)$ where $z_{0}=$ the initial value of $\mathrm{z}$, and $z_{i}=$ the value of the complex quantity $z$ at the $i$ th iteration. For example, the Mandelbrot's self-squared function for generating fractals is: $f(z)=z^{2}+c$, where $z$ and $c$ are both complex quantities.

We propose the use of the transformation function $z \rightarrow \log \left(z^{n}+c\right)$ for generating fractal images with respect to Ishikawa iterates, where $z$ and $c$ are the complex quantities and $n$ is a real number. Each of these fractal images is constructed as a two-dimensional array of pixels. Each pixel is represented by a pair of $(x, y)$ coordinates. The complex quantities $z$ and $c$ can be represented as:

$$
\begin{aligned}
& z=z_{x}+i z_{y} \\
& c=c_{x}+i c_{y}
\end{aligned}
$$

where $i=\sqrt{(-1)}$ and $z_{x}, c_{x}$ are the real parts and $z_{y}$ $\& c_{y}$ are the imaginary parts of $z$ and $c$, respectively. The pixel coordinates $(x, y)$ may be associated with $\left(c_{x}, c_{y}\right)$ or $\left(z_{x}, z_{y}\right)$.

Based on this concept, the fractal images can be classified as follows:

(a) c-plane fractals, wherein $(x, y)$ is a function of $\left(c_{x}, c_{y}\right)$

(b) z-plane fractals, wherein $(x, y)$ is a function of $\left(z_{x}, z_{y}\right)$.

In the literature, the fractals for $n=2$ in $z$ plane are termed as the Mandelbrot set while the fractals for $n=2$ in $c$ plane are known as Julia sets

2.2 Generating the fractals: Fractals have been generated from $z \rightarrow z^{-n}+c$ using escape-time techniques, for example by Gujar etal.[8, 9] and Glynn [10]. We have used in this paper escape time criteria of Relative Superior Ishikawa iterates for function $z \rightarrow \log \left(z^{n}+c\right)$.

Escape Criterion for Quadratics: Suppose that $|z|>\max \left\{|c|, 2 / s, 2 / s^{\prime}\right\}$, then $\left|z_{n}\right|>(1+\lambda)^{n}|z|$ and $\left|z_{n}\right| \rightarrow \infty$ as $n \rightarrow \infty$.So, $|z| \geq|c|$ and $|z|>2 / s$ as well as $|z|>2 / s^{\prime}$ shows the escape criteria for quadratics.

Escape Criterion for Cubics: Suppose $|z|>\max \left\{|b|,(|a|+2 / s)^{1 / 2},\left(|a|+2 / s^{\prime}\right)^{1 / 2}\right\} \quad$ then $\left|z_{n}\right| \rightarrow \infty$ as $n \rightarrow \infty$. This gives an escape criterion for cubic polynomials
General
Escape
Criterion:
Consider $|z|>\max \left\{|c|,(2 / s)^{1 / n},\left(2 / s^{\prime}\right)^{1 / n}\right\}$ then $\left|z_{n}\right| \rightarrow \infty$ as $n \rightarrow \infty$ is the escape criterion. (Escape Criterion derived in [23, 27]).

Note that the initial value $z_{0}$ should be infinity, since infinity is the critical point of $z \rightarrow \log \left(z^{n}+c\right)$. However instead of starting with $z_{0}=$ infinity, it is simpler to start with $z_{1}=c$, which yields the same result. (A critical point of $\mathrm{z} \rightarrow \mathrm{F}(\mathrm{z})+\mathrm{c}$ is a point where $\mathrm{F}^{\prime}(z)=0$ ). The role of critical points is explained in [1].

\subsection{Midgets of Relative Superior Mandelbrot Set:}

The midgets of the RSM set are the small mini Mandelbrot set like images found in the scattered surroundings of the RSM set. The study of midgets in the Mandelbrot set is given by Philip[20] and Romera [24]. 
We have generated numerous RSM sets for $Q_{c}(\mathrm{z})$ for various values of $n$. We find fascinating new fractals having several effectively different geometric shapes. However, we have selected a few figures to study midgets in RSM sets for $Q_{c}(\mathrm{z})$ with $\mathrm{n}=2,4,6$ and 8 , wherein $\mathrm{s}=0.8$ and $s^{\prime}=0.9$. The Mandelbrot set consists of many small decorations or bulbs attached to the main body. The main body is called "main cardioid" by Devaney [4]-[7] and simply "cardioid" by Philip [20]. Similarly, the biggest bulb attached to the main cardiod is named as "period-2 bulb" by Devaney and "head" by Philip.

Further, the small decorations attached to the main cardiod are called "atom-n" by Philip[20], and "period-n bulb" by Devaney [4], where $n$ is the period of the bulb. Each period- $n$ bulb has a main antenna attached to it. This antenna is named as "spikes" or "tendrils" by Philip [20]. Devaney[4] has shown that the main antenna consists of a number of spokes attached; the number of spokes is the same as on the period of the corresponding bulb. In our study, we largely follow the Devaney's nomenclature and occasionally that of Philip[20].

The RSM set for $Q_{c}(\mathrm{z})$ with degree n contains nprimary bulbs. We find that a period- 2 bulb is connected to each of these (n - 1) primary bulbs. Other period-n bulbs vanish as the value of $s$ comes nearer to 0 . Further, the main antenna looks disconnected for small values of $\mathrm{s}$ and $s^{\prime}$.

Now we consider the following two cases.

\section{Case $I\left(s=1, s^{\prime}=1\right.$ special case $)$}

We observe that, when $s=1$ and $s^{\prime}=1$, the RSM set for $n>2$ is the Mandelbrot set of $n^{\text {th }}$ order having $n^{\text {th }}$ main cardioids. On zooming, we find only one kind of midgets, i.e. mini Mandelbrot sets of $\mathrm{n}^{\text {th }}$ order, which are near the apex or end of the branch.

\section{Case II $\left(0<s<1,0<s^{\prime}<1\right.$, general case $)$}

For $n>2$, we observe that, the RSM set of $n^{\text {th }}$ order contains $n^{\text {th }}$ distinct main cardioids (see Figs. 2 and 3). On zooming the RSM set for $n>2$, we get the midgets of mini Mandelbrot set on the main antennas of period-n bulbs. A remarkable feature is observed that, all the midgets are of order 2 , i.e., the order of each of the midgets does not depend on the degree of the polynomial $Q_{c}(\mathrm{z})$. We notice that the order of midgets is not independent of the degree of the polynomial $Q_{c}(\mathrm{z})$ when $s=1, s^{\prime}=1$ ( $c f$. Case I).

These observations show that, at least, some of the RSM sets are effectively different from the usual Mandelbrot sets.

\section{GEOMETRY OF RELATIVE SUPERIOR MANDELBROT SETS AND RELATIVE SUPERIOR JULIA SETS:}

The fractals generated from the equation

$z \rightarrow \log \left(z^{n}+c\right)$ possesses rotational as well as reflection symmetry. As conjectured by Gujar and Bhavsar in $[8,9]$, the fractals generated with the exponent $n$ are $(n+1)$ way rotationally symmetric.

\subsection{Relative Superior Mandelbrot sets:}

- There are several secondary ovoids or bulbs attached with the main body or the central ovoid. Here, the number of major secondary lobe is (n-1). Besides, this main body of Mandelbrot set is observed to be symmetrical about real axis.

- $\quad$ As the value of $s$ tend to 1 and $s^{\prime}$ tends to 1 , the Relative Superior Mandelbrot sets of logarithmic function converts to the general Mandelbrot sets of logarithmic function, hence we can say that the Relative Superior Mandelbrot sets of logarithmic function is the general case of the usual Mandelbrot sets of logarithmic function.

- In case of quadratic polynomial, among all the secondary ovoids, only one that is the major secondary ovoid happens to be quite larger than rest of the other ovoids. Moreover, as the value of $s$ and $s^{\prime}$ changes, the rest of the ovoids vanishes except the major secondary ovoid.

- In case of the cubic polynomial, the central body is bifurcated into two lobes, where each primary ovoid contains a major secondary ovoid along with other ovoids. As, the value of $s$ and $s^{\prime}$ varies, then the major secondary lobes also shows the bifurcations.

- In case of biquadractic function, the central body is bifurcated into three lobes, where two major lobes contains bigger secondary major ovoid while the third one which remains comparatively a smaller lobe, has a very small secondary major lobe.

- We also observe that the Relative Superior Mandelbrot sets of logarithmic function had their Midgets for quadratic, Biquadratic and other even valued function.

\section{FIXED POINTS}

\subsection{Fixed points of quadratic polynomial}

Table 1: Orbit of $F(z)$ at $s=1$ and $s^{\prime}=1$ for $\left(\mathrm{z}_{0}=1.115279339+0.004573602931 \mathrm{i}\right)$

\begin{tabular}{|l|l|l|l|}
\hline $\begin{array}{l}\text { Number of } \\
\text { iteration } i\end{array}$ & $|\mathrm{~F}(\mathrm{z})|$ & $\begin{array}{l}\text { Number of } \\
\text { iteration } \mathrm{i}\end{array}$ & $|\mathrm{F}(\mathrm{z})|$ \\
\hline 205 & 2.2608 & 215 & 2.2609 \\
\hline 206 & 2.2605 & 216 & 2.2607 \\
\hline 207 & 2.2609 & 217 & 2.2608 \\
\hline 208 & 2.2611 & 218 & 2.261 \\
\hline 209 & 2.2607 & 219 & 2.2608 \\
\hline 210 & 2.2606 & 220 & 2.2608 \\
\hline 211 & 2.261 & 221 & 2.2608 \\
\hline 212 & 2.261 & 222 & 2.2608 \\
\hline 213 & 2.2607 & 223 & 2.2608 \\
\hline 214 & 2.2607 & 224 & 2.2608 \\
\hline
\end{tabular}


We skipped 204 iterations and after 219 iterations value converges

Figure 1. : Orbit of $F(z)$ at $s=1$ and $s^{\prime}=1$ for $\left(\mathrm{z}_{0}=1.115279339+0.004573602931 \mathrm{i}\right)$

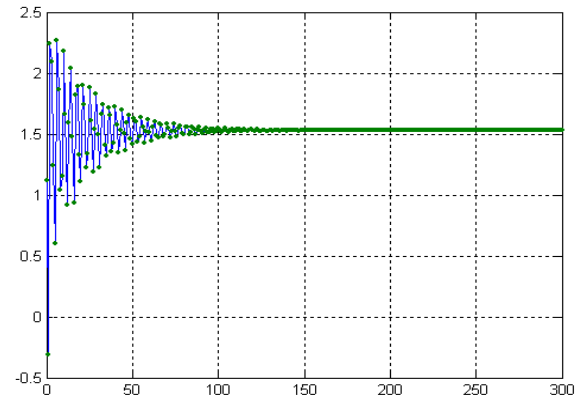

Table 2: Orbit of $F(z)$ at $\mathbf{s}=\mathbf{0 . 5}$ and $\mathrm{s}^{\prime}=\mathbf{0 . 2}$ for $\left(z_{0}=-\mathbf{0 . 2 7 1 9 7 2 0 5 2 7 + 0 . 0 0 6 1 8 9 7 4 0 1 9 7 i )}\right.$

\begin{tabular}{|l|l|l|l|}
\hline $\begin{array}{l}\text { Number of } \\
\text { iteration } i\end{array}$ & $\mid \mathrm{F}(\mathrm{z})$ & $\begin{array}{l}\text { Number of } \\
\text { iteration } \mathrm{i}\end{array}$ & $|\mathrm{F}(\mathrm{z})|$ \\
\hline 1 & 0.27204 & 8 & 0.77381 \\
\hline 2 & 1.0321 & 9 & 0.77413 \\
\hline 3 & 0.92033 & 10 & 0.77418 \\
\hline 4 & 0.7621 & 11 & 0.77419 \\
\hline 5 & 0.75008 & 12 & 0.77418 \\
\hline 6 & 0.78331 & 13 & 0.77418 \\
\hline 7 & 0.77306 & 14 & 0.77418 \\
\hline
\end{tabular}

Here we observe that the value converges to a fixed point after 10 iterations

Figure 2. Orbit of $F(z)$ at $s=0.5$ and $s^{\prime}=0.2$ for $\left(z_{0}=\mathbf{- 0 . 2 7 1 9 7 2 0 5 2 7 + 0 . 0 0 6 1 8 9 7 4 0 1 9 7 i )}\right.$

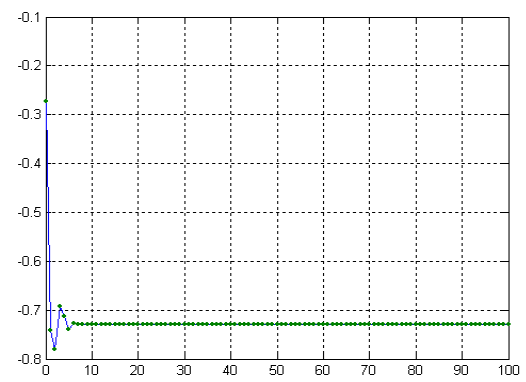

Table 3: Orbit of $F(z)$ at $s=0.5$ and $s^{\prime}=0.4$ for $\left(\mathrm{z}_{0}=\mathbf{0 . 1 2 2 1 5 0 1 8 4 4 - 0 . 0 0 1 1 9 3 8 8 0 0 4 9 i )}\right.$

\begin{tabular}{|l|l|l|l|}
\hline $\begin{array}{l}\text { Number } \\
\text { of } \\
\text { iteration } \mathrm{i}\end{array}$ & $|\mathrm{F}(\mathrm{z})|$ & $\begin{array}{l}\text { Number } \\
\text { of } \\
\text { iteration } \mathrm{i}\end{array}$ & $|\mathrm{F}(\mathrm{z})|$ \\
\hline 1 & 0.12216 & 9 & 1.7162 \\
\hline 2 & 1.3071 & 10 & 1.716 \\
\hline 3 & 1.6111 & 11 & 1.7159 \\
\hline 4 & 1.6914 & 12 & 1.7158 \\
\hline 5 & 1.7096 & 13 & 1.7157 \\
\hline 6 & 1.7151 & 14 & 1.7157 \\
\hline 7 & 1.7166 & 15 & 1.7157 \\
\hline
\end{tabular}

$$
\begin{array}{|l|l|l|l|}
\hline 8 & 1.7167 & 16 & 1.7157 \\
\hline
\end{array}
$$

Here the value converges to a fixed point after 13 iterations

Figure 3. Orbit of $F(z)$ at $s=0.5$ and $s^{\prime}=0.4$ for $\left(\mathrm{z}_{0}=\mathbf{0 . 1 2 2 1 5 0 1 8 4 4 - 0 . 0 0 1 1 9 3 8 8 0 0 4 9 i )}\right.$

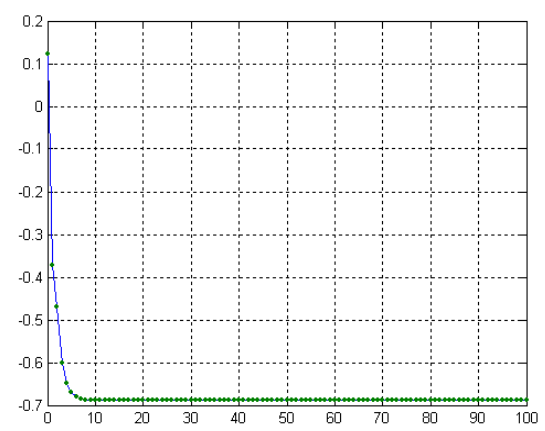

Table 4 Orbit of $F(z)$ at $\mathbf{s}=\mathbf{0 . 8}$ and $\mathbf{s}^{\prime}=\mathbf{0 . 4}$ for $\left(\mathrm{z}_{0}=\mathbf{0 . 1 1 6 8 7 5 2 4 7 + 0 . 0 0 8 8 7 2 3 1 5 0 3 5 \mathrm { i } )}\right.$

\begin{tabular}{|l|l|l|l|}
\hline $\begin{array}{l}\text { Number } \\
\text { of } \\
\text { iteration } \mathrm{i}\end{array}$ & $|\mathrm{F}(\mathrm{z})|$ & $\begin{array}{l}\text { Number } \\
\text { of } \\
\text { iteration i }\end{array}$ & $|\mathrm{F}(\mathrm{z})|$ \\
\hline 1 & 0.11721 & 7 & 1.7157 \\
\hline 2 & 2.1293 & 8 & 1.7157 \\
\hline 3 & 1.7603 & 9 & 1.7157 \\
\hline 4 & 1.7258 & 10 & 1.7157 \\
\hline 5 & 1.7188 & 11 & 1.7157 \\
\hline 6 & 1.7164 & 12 & 1.7157 \\
\hline
\end{tabular}

Here the value converges to a fixed point after 07 iterations

Figure 4. Orbit of $F(z)$ at $s=0.8$ and $s^{\prime}=0.4$ for $\left(\mathrm{z}_{0}=\mathbf{0 . 1 1 6 8 7 5 2 4 7 + 0 . 0 0 8 8 7 2 3 1 5 0 3 5 \mathrm { i } )}\right.$

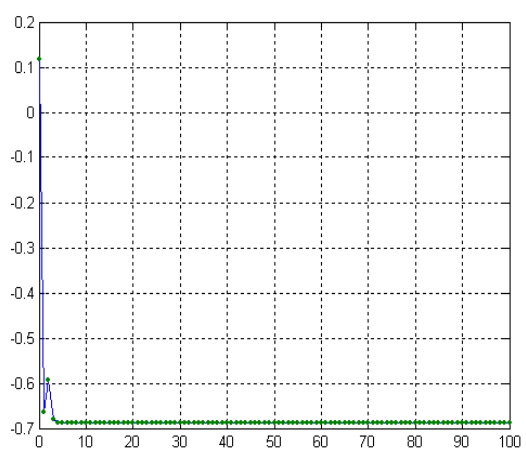

4.2 Fixed points of Cubic polynomial

Table 1: Orbit of $F(z)$ at $s=1$ and $s^{\prime}=1$ for $\left(\mathrm{z}_{0}=1.159503886+0.09059823882 \mathrm{i}\right)$

\begin{tabular}{|l|l|l|l|}
\hline $\begin{array}{l}\text { Number of } \\
\text { iteration } i\end{array}$ & $\mid \mathrm{F}(\mathrm{z})$ & $\begin{array}{l}\text { Number of } \\
\text { iteration } \mathrm{i}\end{array}$ & $|\mathrm{F}(\mathrm{z})|$ \\
\hline 1 & 1.163 & 10 & 4.5376 \\
\hline 2 & 1.878 & 11 & 4.5371 \\
\hline 3 & 3.1287 & 12 & 4.5368 \\
\hline 4 & 4.4407 & 13 & 4.5367 \\
\hline 5 & 4.637 & 14 & 4.5367 \\
\hline 6 & 4.6023 & 15 & 4.5367 \\
\hline 7 & 4.5678 & 16 & 4.5367 \\
\hline
\end{tabular}




\begin{tabular}{|l|l|l|l|}
\hline 8 & 4.5502 & 17 & 4.5367 \\
\hline 9 & 4.5423 & 18 & 4.5367 \\
\hline
\end{tabular}

Here we observe that the value converges to a fixed point after 13 iterations

Figure 1. Orbit of $F(z)$ at $\mathbf{s}=\mathbf{1}$ and $\mathbf{s}^{\prime}=\mathbf{1}$ for $\left(z_{0}=1.159503886+0.09059823882 i\right)$

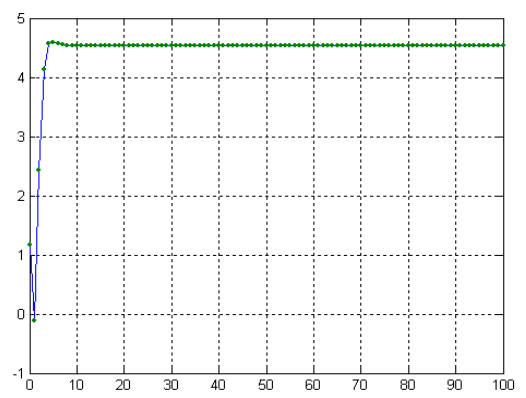

Table 2: Orbit of $\mathrm{F}(\mathrm{z})$ at $\mathrm{s}=\mathbf{0 . 5}$ and $\mathrm{s}^{\prime}=\mathbf{0 . 1}$ for

\begin{tabular}{|l|l|l|l|}
\multicolumn{5}{|c}{$\left(\mathbf{z}_{\mathbf{0}}=\mathbf{0 . 7 3 9 1 6 4 0 3 6 + 0 . 0 3 2 4 9 6 0 5 1 2 9 i}\right)$} \\
\hline $\begin{array}{l}\text { Number of } \\
\text { iteration i }\end{array}$ & $|\mathrm{F}(\mathrm{z})|$ & $\begin{array}{l}\text { Number of } \\
\text { iteration } \mathrm{i}\end{array}$ & $|\mathrm{F}(\mathrm{z})|$ \\
\hline 1 & 0.73988 & 12 & 0.80468 \\
\hline 2 & 0.6624 & 13 & 0.80488 \\
\hline 3 & 2.106 & 14 & 0.80534 \\
\hline 4 & 0.84776 & 15 & 0.80495 \\
\hline 5 & 1.0982 & 16 & 0.80517 \\
\hline 6 & 0.33581 & 17 & 0.80507 \\
\hline 7 & 1.019 & 18 & 0.80511 \\
\hline 8 & 0.69424 & 19 & 0.80509 \\
\hline 9 & 0.84457 & 20 & 0.8051 \\
\hline 10 & 0.79229 & 21 & 0.8051 \\
\hline 11 & 0.80849 & 22 & 0.8051 \\
\hline
\end{tabular}

Here we observe that the value converges to a fixed point after 20 iterations

Figure 2 Orbit of $\mathrm{F}(\mathrm{z})$ at $\mathrm{s}=\mathbf{0 . 5}$ and $\mathrm{s}^{\prime}=\mathbf{0 . 1}$ for $\left(\mathrm{z}_{0}=0.739164036+0.03249605129 \mathrm{i}\right)$

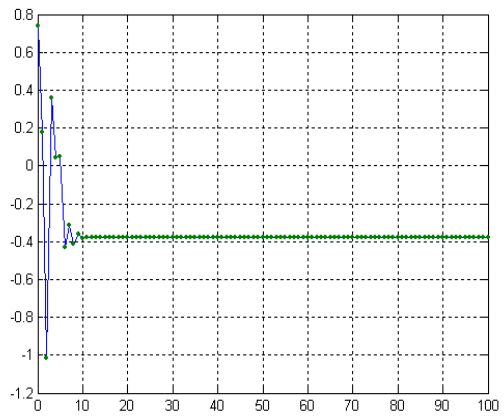

Table 3: Orbit of $F(z)$ at $s=0.5$ and $s^{\prime}=0.3$ for $\left(\mathrm{z}_{0}=0.4806782686+0.02610157227 \mathrm{i}\right)$

\begin{tabular}{|l|l|l|l|}
\hline $\begin{array}{l}\text { Number of } \\
\text { iteration i }\end{array}$ & $|\mathrm{F}(\mathrm{z})|$ & $\begin{array}{l}\text { Number of } \\
\text { iteration } \mathrm{i}\end{array}$ & $|\mathrm{F}(\mathrm{z})|$ \\
\hline 20 & 0.80485 & 27 & 0.8051 \\
\hline 21 & 0.80502 & 28 & 0.80509 \\
\hline 22 & 0.80512 & 29 & 0.80509 \\
\hline 23 & 0.80516 & 30 & 0.80509 \\
\hline
\end{tabular}

\begin{tabular}{|l|l|l|l|}
\hline 24 & 0.80516 & 31 & 0.80509 \\
\hline 25 & 0.80514 & 32 & 0.8051 \\
\hline 26 & 0.80512 & 33 & 0.8051 \\
\hline
\end{tabular}

We skipped 19 iterations and after 32 iterations value converges

Figure 3. Orbit of $F(z)$ at $s=0.5$ and $s^{\prime}=0.3$ for $\left(\mathrm{z}_{0}=\mathbf{0 . 4 8 0 6 7 8 2 6 8 6 + 0 . 0 2 6 1 0 1 5 7 2 2 7 \mathrm { i } )}\right.$

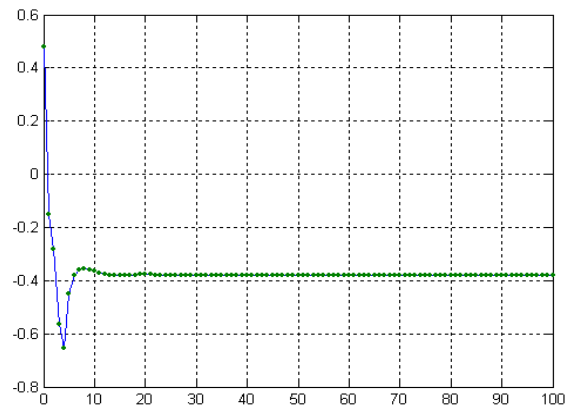

Table 4 Orbit of $F(z)$ at $s=0.8$ and $s^{\prime}=0.3$ for $\left(\mathrm{z}_{0}=1.694305119-0.002625316039 \mathrm{i}\right)$

\begin{tabular}{|l|l|l|l|}
\hline $\begin{array}{l}\text { Number of } \\
\text { iteration i }\end{array}$ & $|\mathrm{F}(\mathrm{z})|$ & $\begin{array}{l}\text { Number of } \\
\text { iteration } \mathrm{i}\end{array}$ & $|\mathrm{F}(\mathrm{z})|$ \\
\hline 15 & 4.5539 & 24 & 4.5374 \\
\hline 16 & 4.5489 & 25 & 4.5372 \\
\hline 17 & 4.5452 & 26 & 4.537 \\
\hline 18 & 4.5427 & 27 & 4.5369 \\
\hline 19 & 4.5409 & 28 & 4.5368 \\
\hline 20 & 4.5396 & 29 & 4.5368 \\
\hline 21 & 4.5387 & 30 & 4.5368 \\
\hline 22 & 4.5381 & 31 & 4.5367 \\
\hline 23 & 4.5377 & 32 & 4.5367 \\
\hline
\end{tabular}

We skipped 14 iterations and after 31 iterations value converges

Figure 4. Orbit of $F(z)$ at $\mathbf{s}=\mathbf{0 . 8}$ and $\mathbf{s}^{\prime}=\mathbf{0 . 3}$ for $\left(z_{0}=1.694305119-0.002625316039 i\right)$

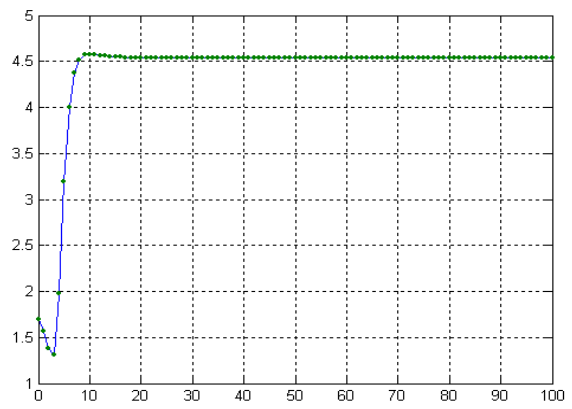

4.3 Fixed points of Bi-quadratic polynomial

Table 1: Orbit of $F(z)$ at $s=1$ and $s^{\prime}=1$ for $\left(z_{0}=1.36233755-0.02045744357 i\right)$

\begin{tabular}{|c|c|c|c|}
\hline $\begin{array}{l}\text { Number of } \\
\text { iteration i }\end{array}$ & $|\mathrm{F}(\mathrm{z})|$ & $\begin{array}{l}\text { Number of } \\
\text { iteration i }\end{array}$ & $|\mathrm{F}(\mathrm{z})|$ \\
\hline 1 & 1.3625 & 8 & 8.6066 \\
\hline 2 & 1.048 & 9 & 8.6118 \\
\hline 3 & 2.6441 & 10 & 8.6129 \\
\hline 4 & 6.0664 & 11 & 8.6131 \\
\hline 5 & 7.9792 & 12 & 8.6132 \\
\hline 6 & 8.4729 & 13 & 8.6132 \\
\hline
\end{tabular}




\section{7}

8.5828

14

8.6132

Here we observe that the value converges to a fixed point after 12 iterations

Figure 1 Orbit of $F(z)$ at $s=1$ and $s^{\prime}=1$ for $\left(\mathrm{z}_{0}=1.36233755-0.02045744357 \mathrm{i}\right)$

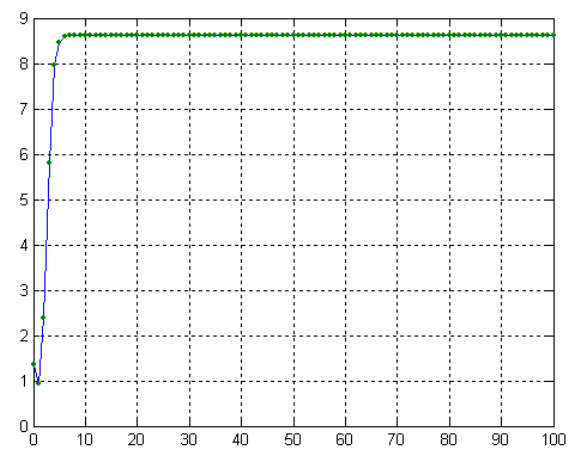

Table 2: Orbit of $F(z)$ at $s=0.5$ and $s^{\prime}=0.1$ for $\left(\mathrm{z}_{0}=\mathbf{0 . 4 2 8 3 8 5 4 2 2 8 - 0 . 0 3 9 9 1 1 8 8 0 0 2 i}\right)$

\begin{tabular}{|l|l|l|l|}
\hline $\begin{array}{l}\text { Number of } \\
\text { iteration } \mathrm{i}\end{array}$ & $\mid \mathrm{F}(\mathrm{z})$ & $\begin{array}{l}\text { Number of } \\
\text { iteration } \mathrm{i}\end{array}$ & $|\mathrm{F}(\mathrm{z})|$ \\
\hline 30 & 0.88893 & 37 & 0.88866 \\
\hline 31 & 0.88848 & 38 & 0.88878 \\
\hline 32 & 0.88883 & 39 & 0.88874 \\
\hline 33 & 0.88881 & 40 & 0.8887 \\
\hline 34 & 0.8886 & 41 & 0.88876 \\
\hline 35 & 0.8888 & 42 & 0.88873 \\
\hline 36 & 0.88876 & 43 & 0.88873 \\
\hline
\end{tabular}

We skipped 29 iterations and after 42 iterations value converges

Figure 2. : Orbit of $F(z)$ at $\mathbf{s}=\mathbf{0 . 5}$ and $\mathbf{s}^{\prime}=\mathbf{0 . 1}$ for $\left(\mathrm{z}_{0}=\mathbf{0 . 4 2 8 3 8 5 4 2 2 8 - 0 . 0 3 9 9 1 1 8 8 0 0 2 \mathrm { i } )}\right.$

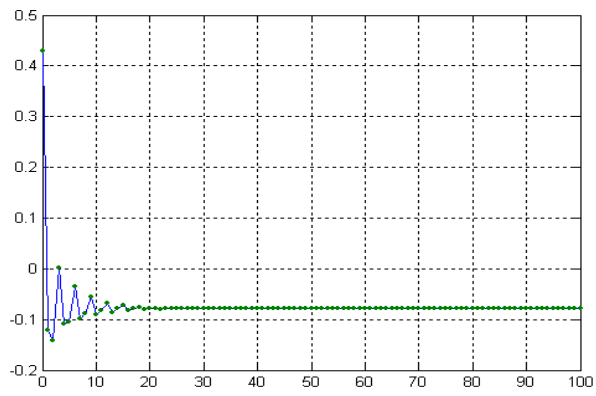

Table 3: Orbit of $F(z)$ at $s=0.5$ and $s^{\prime}=0.3$ for $\left(\mathrm{z}_{0}=\mathbf{0 . 3 0 8 8 0 8 1 8 9 4 - 0 . 0 1 0 1 7 9 1 7 8 3 6 i )}\right.$

\begin{tabular}{|l|l|l|l|}
\hline $\begin{array}{l}\text { Number of } \\
\text { iteration } \mathrm{i}\end{array}$ & $|\mathrm{F}(\mathrm{z})|$ & $\begin{array}{l}\text { Number of } \\
\text { iteration } \mathrm{i}\end{array}$ & $|\mathrm{F}(\mathrm{z})|$ \\
\hline 11 & 0.89619 & 20 & 0.88834 \\
\hline 12 & 0.8852 & 21 & 0.88897 \\
\hline 13 & 0.88884 & 22 & 0.88867 \\
\hline 14 & 0.89048 & 23 & 0.88868 \\
\hline 15 & 0.88673 & 24 & 0.88882 \\
\hline 16 & 0.8901 & 25 & 0.88866 \\
\hline 17 & 0.88822 & 26 & 0.88877 \\
\hline 18 & 0.88861 & 27 & 0.88873 \\
\hline
\end{tabular}
19
\begin{tabular}{|l|l|}
\hline 0.88914 & 28 \\
\hline
\end{tabular}
0.88873

We skipped 10 iterations and after 27 iterations value converges

Figure 3. Orbit of $F(z)$ at $\mathbf{s}=\mathbf{0 . 5}$ and $s^{\prime}=0.3$ for $\left(\mathrm{z}_{0}=\mathbf{0 . 3 0 8 8 0 8 1 8 9 4 - 0 . 0 1 0 1 7 9 1 7 8 3 6 i )}\right.$

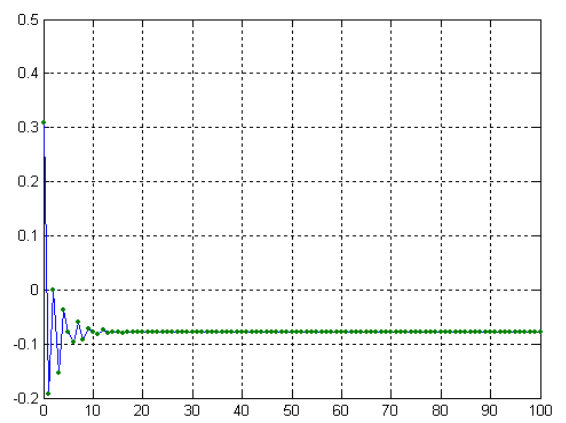

Table 4 Orbit of $\mathrm{F}(\mathrm{z})$ at $\mathrm{s}=\mathbf{0 . 8}$ and $\mathrm{s}^{\prime}=\mathbf{0 . 3}$ for $\left(\mathrm{z}_{0}=\mathbf{0 . 4 0 5 7 8 1 9 2 8 6 - 0 . 0 1 2 9 0 9 3 1 2 1 i}\right)$

\begin{tabular}{|l|l|l|l|}
\hline $\begin{array}{l}\text { Number of } \\
\text { iteration } \mathrm{i}\end{array}$ & $|\mathrm{F}(\mathrm{z})|$ & $\begin{array}{l}\text { Number of } \\
\text { iteration } \mathrm{i}\end{array}$ & $|\mathrm{F}(\mathrm{z})|$ \\
\hline 11 & 8.4042 & 20 & 8.6122 \\
\hline 12 & 8.5055 & 21 & 8.6127 \\
\hline 13 & 8.5579 & 22 & 8.6129 \\
\hline 14 & 8.5848 & 23 & 8.613 \\
\hline 15 & 8.5986 & 24 & 8.6131 \\
\hline 16 & 8.6057 & 25 & 8.6131 \\
\hline 17 & 8.6094 & 26 & 8.6132 \\
\hline 18 & 8.6112 & 27 & 8.6132 \\
\hline
\end{tabular}

We skipped 10 iterations and after 26 iterations value converges

Figure 4. Orbit of $F(z)$ at $\mathbf{s}=\mathbf{0 . 8}$ and $\mathbf{s}^{\prime}=\mathbf{0 . 3}$ for $\left(\mathrm{z}_{0}=\mathbf{0 . 4 0 5 7 8 1 9 2 8 6 - 0 . 0 1 2 9 0 9 3 1 2 1 i}\right)$

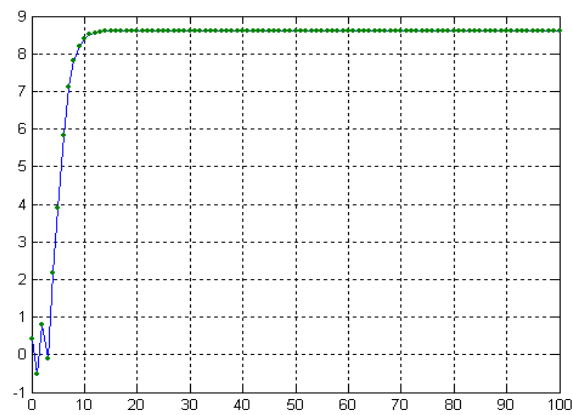

\section{GENERATION OF RELATIVE} SUPERIOR MANDELBROT SETS:

We generate Relative Superior Mandelbrot Sets. We present here some Relative Superior Mandelbrot sets for cubic and biquadratic function.

5.1 Relative Superior Mandelbrot Sets for Quadratic function: Figure 1: Relative Superior Mandelbrot Set for $s=s^{\prime}=1$ 


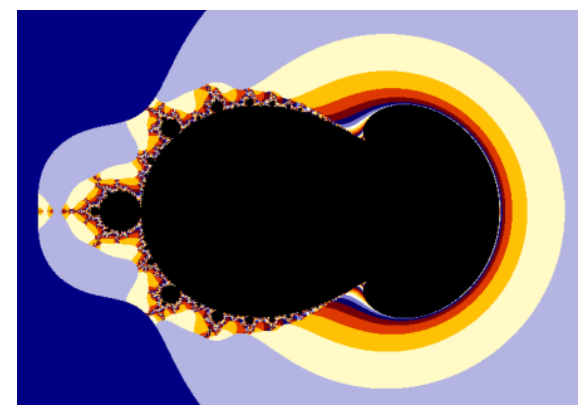

Figure 2: Relative Superior Mandelbrot Set for $s=0.4, s^{\prime}=0.8$

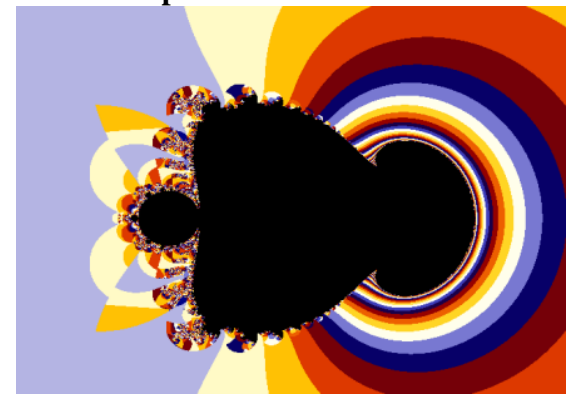

Figure 3: Relative Superior Mandelbrot Set for $s=0.5, s^{\prime}=0.7$

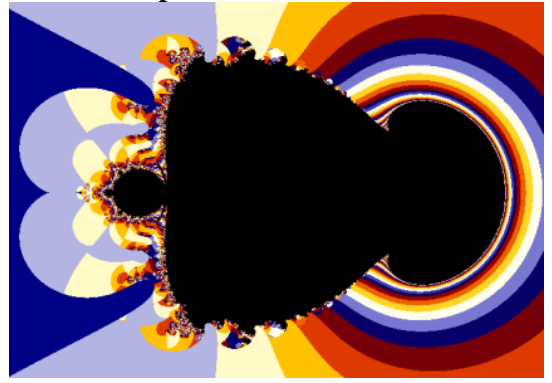

Figure 4: Relative Superior Mandelbrot Set for $s=0.6, s^{\prime}=0.8$

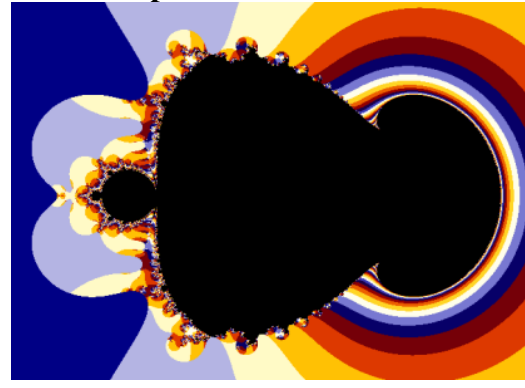

5.2 Relative Superior Mandelbrot Sets for Cubic function:

Figure 1: Relative Superior Mandelbrot Set for $s=s^{\prime}=1$

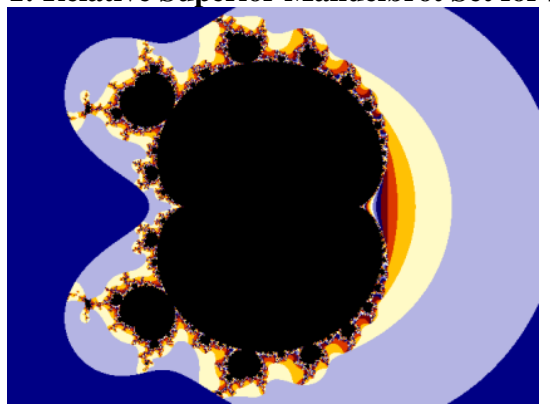

Figure 2: Relative Superior Mandelbrot Set for $s=0.3, s^{\prime}=0.8$

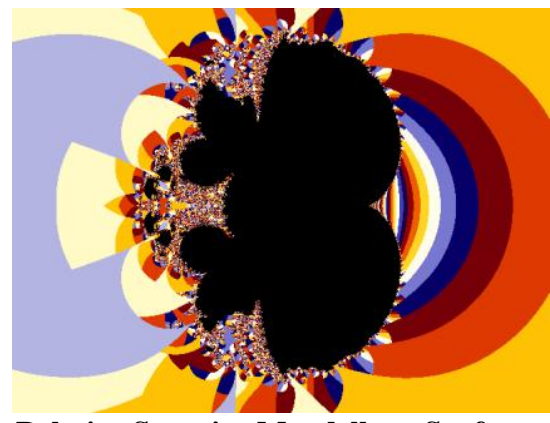

Figure 3: Relative Superior Mandelbrot Set for $s=0.4$ s'=0.6

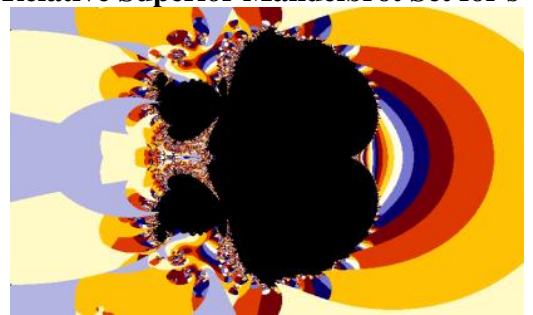

Figure 4: Relative Superior Mandelbrot Set $s=0.4, s^{\prime}=0.8$

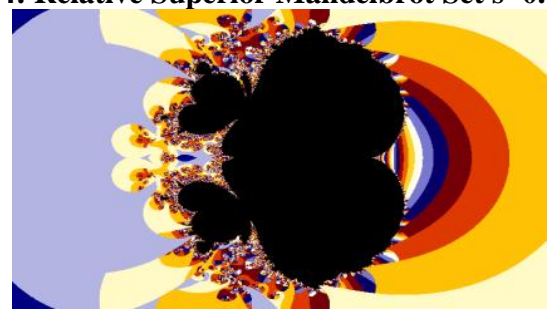

5.3 Relative Superior Mandelbrot Sets for Bi-quadratic function:

Figure 1: Relative Superior Mandelbrot Set for $s=s^{\prime}=1$

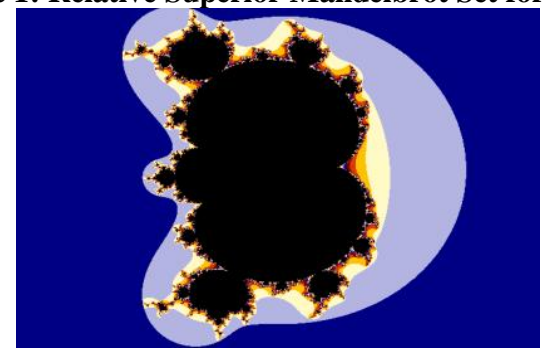

Figure 2: Relative Superior Mandelbrot Set for $s=0.3, s^{\prime}=0.8$

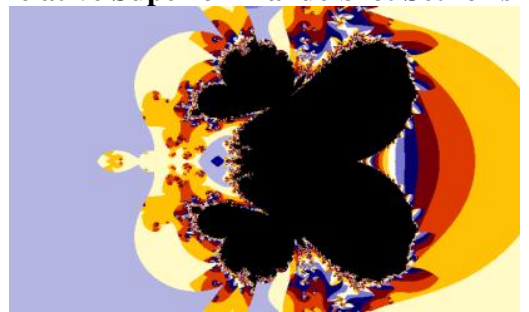

Figure 3: Relative Superior Mandelbrot Set for $\mathrm{s}=\mathbf{0 . 4}, \mathrm{s}^{\prime}=\mathbf{0 . 7}$ 


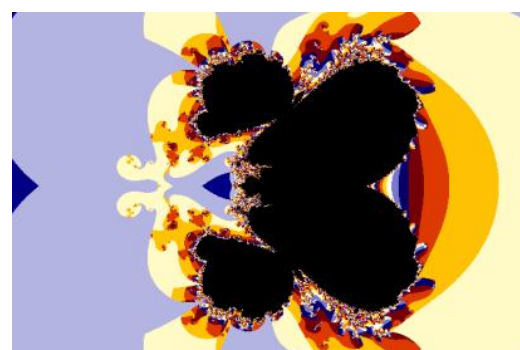

Figure 4: Relative Superior Mandelbrot Set for $s=0.5, s^{\prime}=0.5$

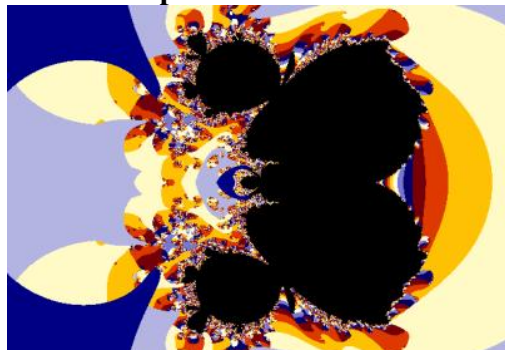

Figure 5: Relative Superior Mandelbrot Set for $n=7, s=1, s^{\prime}=1$

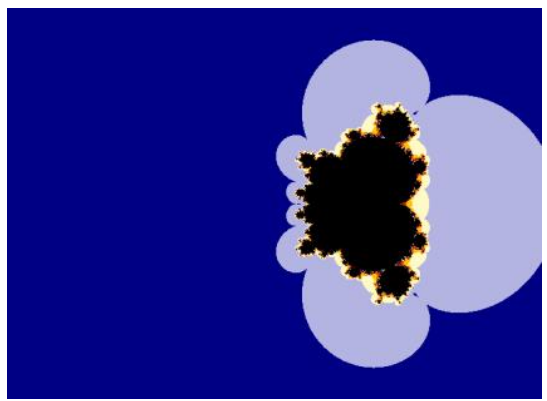

Figure 6: Relative Superior Mandelbroot Set for $n=7, s=0.4$, $s^{\prime}=0.6$

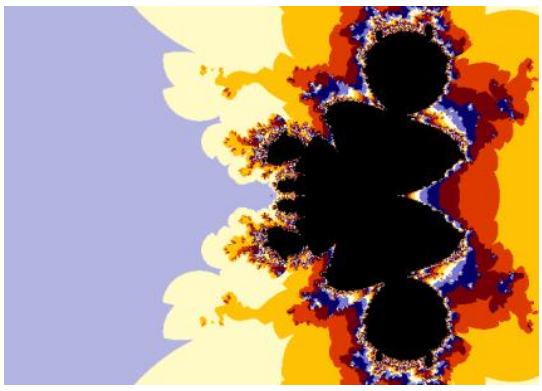

Figure 7: Relative Superior Mandelbrot Set for $n=12, s=0.5$, $s^{\prime}=0.8$

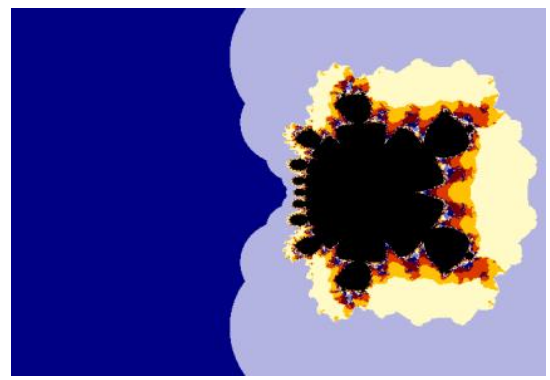

Figure 8: Relative Superior Mandelbrot Set for $n=25, s=0.6$, $\mathrm{s}^{\prime}=\mathbf{0 . 8}$

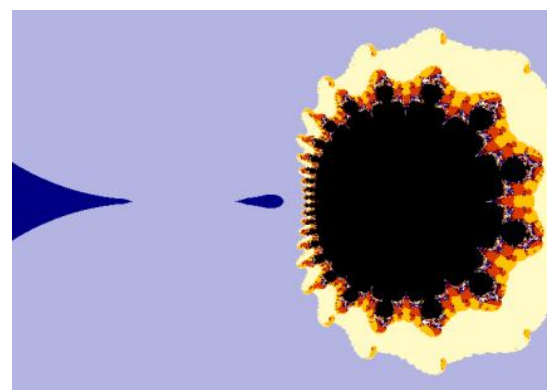

\section{GENERATION OF RELATIVE SUPERIOR JULIA SETS:}

We present here some filled Relative Superior Julia sets for quadratic, cubic and biquadratic function.

6.1 Relative Superior Julia sets for Quadratic function:

Figure 1: Relative Superior Julia Set for $s=0.4, s^{\prime}=0.8$, $\mathrm{c}=0.6777636952+0.007335278698 \mathrm{i}$

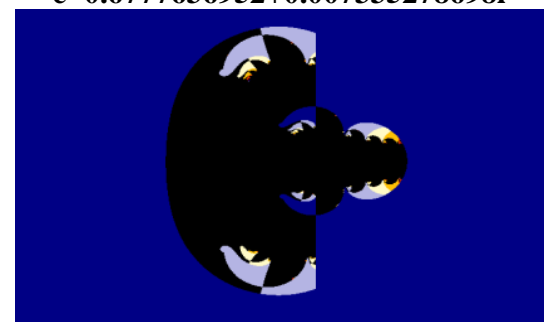

6.2: Relative Superior Julia sets for Cubic function:

Figure 1: Relative Superior Julia Set for $s=0.4, s^{\prime}=0.8$, $c=0.6857349346+0.09564534988 i$

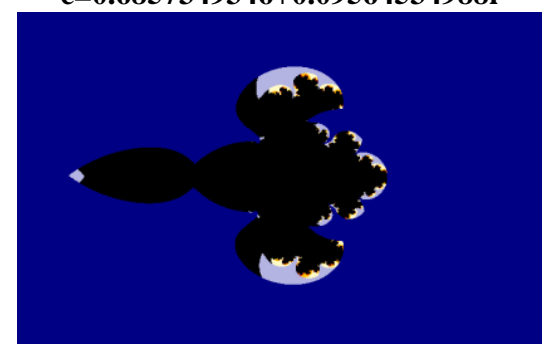

6.3 Relative Superior Julia sets for Bi-quadratic function:

Figure 1: Relative Superior Julia Set for $s=0.4, s^{\prime}=0.8$, c $=0.7741479655+0.01607362203 i$

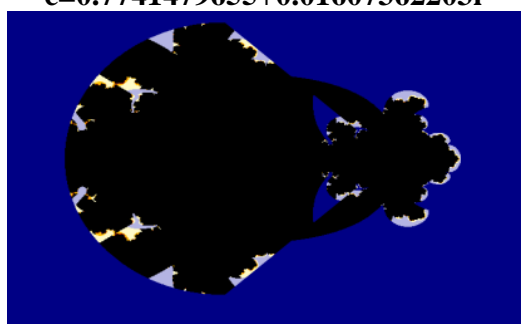

7. RELATIVE SUPERIOR MIDGET OF THE LOGARTHMIC FUNCTION:

7.1 Relative Superior Midget of the quadratic function:

Figure 1: Relative Superior Midget for $s=1, s^{\prime}=1$ 


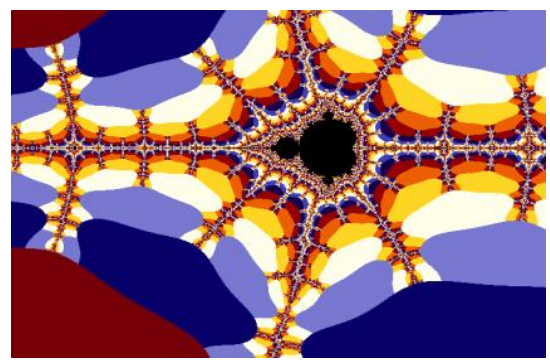

Figure 2: Relative Superior Midget for $s=0.8, s^{\prime}=0.8$

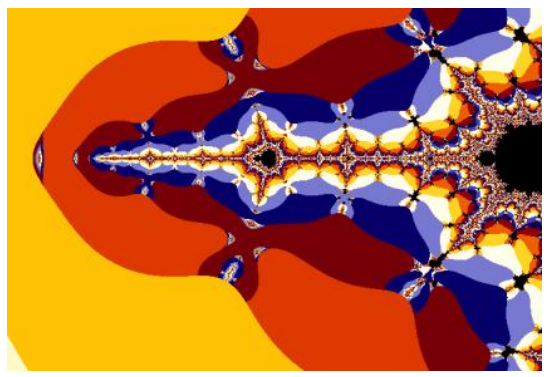

Figure 3: Zoom of Relative Superior Midget for $s=0.8, s^{\prime}=0.8$

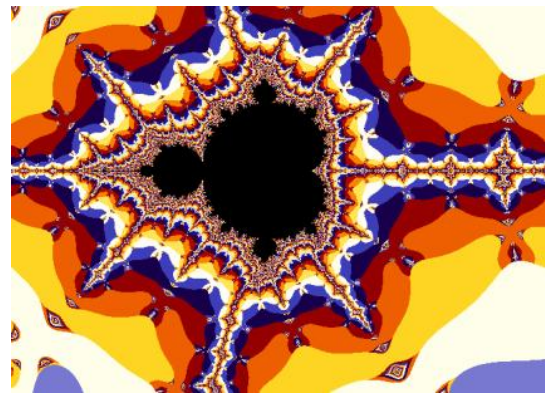

7.2 Relative Superior Midget of the bi-quadratic function:

Figure 1: Relative Superior Midget for $s=1, s^{\prime}=1$

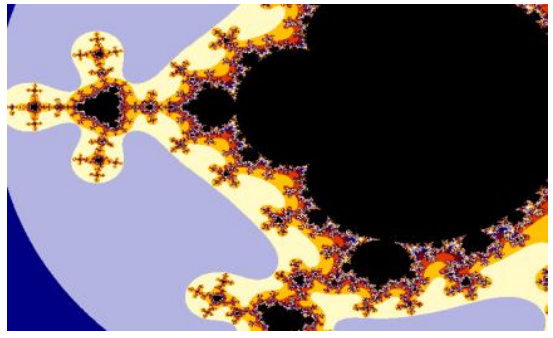

Figure 2: Relative Superior Midget for $s=0.8, s^{\prime}=0.9$

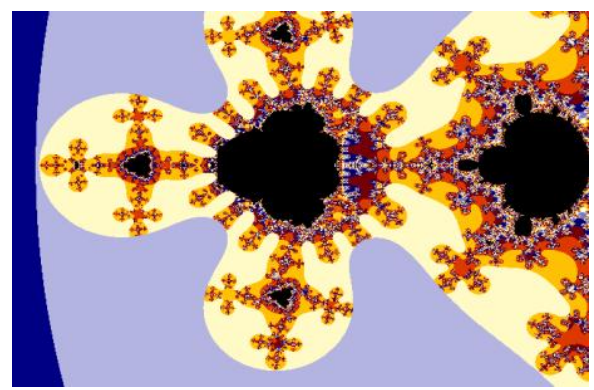

Figure 3: Zoom of Relative Superior Midget for $s=0.8, s^{\prime}=0.9$

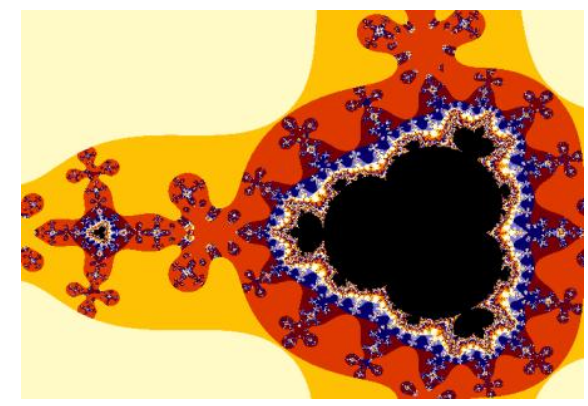

7.3 Relative Superior Midget of the function for $\mathbf{n}=6$

Figure 1: Relative Superior Midget for $s=1, s^{\prime}=1$

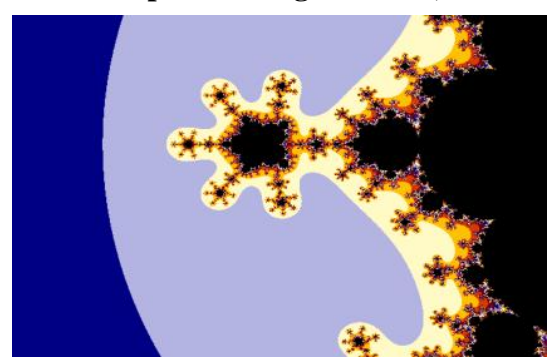

Figure 2: Relative Superior Midget for $s=0.8, s^{\prime}=0.9$

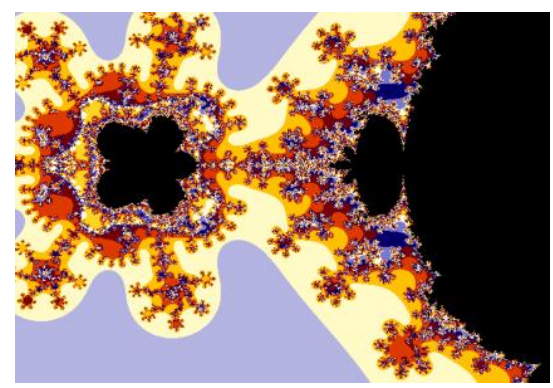

Figure 3: Disconnected bulb of period-3 bulb for $\mathrm{s}=0.8, \mathrm{~s}^{\prime}=0.9$

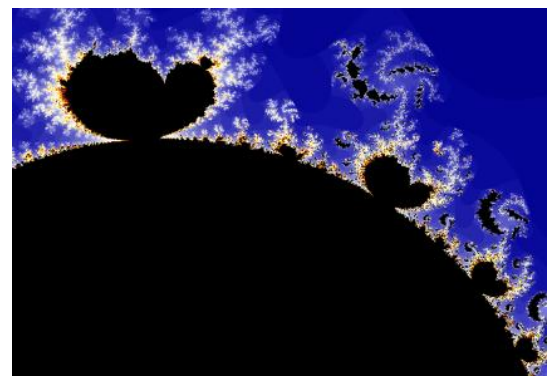

Figure 4: Disconnected bulb of period-5 bulb for $s=0.8, s^{\prime}=0.9$

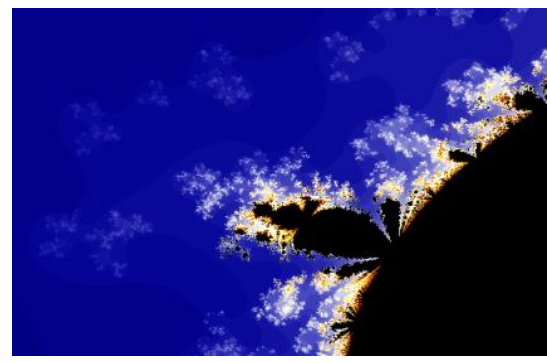


7.3 Relative Superior Julia of Midget of the quadratic function:

Figure 1: Relative Superior Julia Set for $s=0.8, s^{\prime}=0.8$, $c=0.2090087+0.0000122 i$

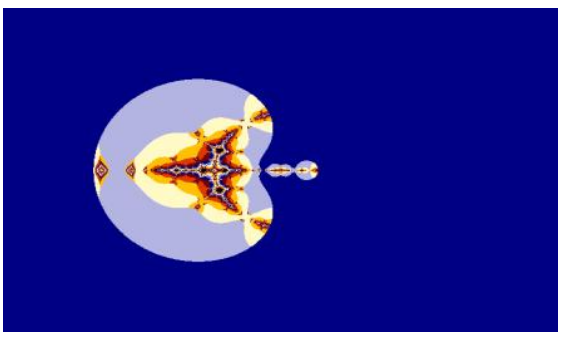

7.4 Relative Superior Julia of Midget of the bi- quadratic function:

Figure 1: Relative Superior Julia Set for $s=0.8, s^{\prime}=0.9$, $c=0.2090087+0.0000122 \mathrm{i}$

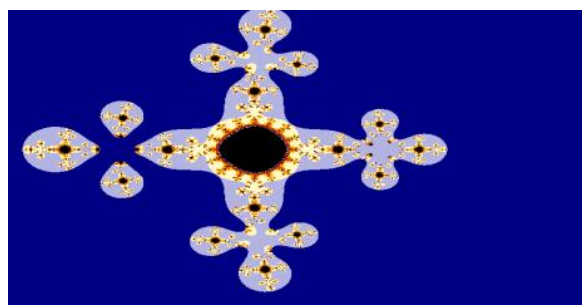

\section{CONCLUSION}

In the dynamics of complex logarithmic polynomial $z \rightarrow \log \left(z^{n}+c\right)$, where $n \geq 2$, the fractals generated with exponent $n$ are found as $(\mathrm{n}+1)$ way rotationally symmetric. There are several ovoids or bulbs attached with the main body. The number of major secondary lobe is $(n-1)$. Besides this, for the polynomial of degree greater than two, the central body is bifurcated into $(n-1)$ lobes.

The midgets observed for the logarithmic function are derived for even polynomials while for the odd function, bulbs gets disconnected.

\section{REFERENCES}

[1] B. Branner, "The Mandelbrot Set", Proceedings of Symposia in Applied Mathematics39 (1989), 75-105.

[2] Robert L. Devaney, "A First Course in Chaotic Dynamical Systems: Theory and Experiment", Addison-Wesley, 1992. MR1202237.

[3] R. L. Devaney, "The fractal geometry of the Mandelbrot set. 2. How to count and how to add. Symposium in Honor of Benoit Mandelbrot", Fractals 3 (1995), no. 4, 629-640. MR1410283(99d:58095)

[4] R. L. Devaney, "The fractal geometry of the Mandelbrot set:I, Period of Bulbs", In Fractals, Graphics and mathematics education, MAA Notes,58(2002), 61-68.

[5] R. L. Devaney and M. Krych, "Dynamics of $\operatorname{Exp}(z)$ ", Ergodic Theory and Dynamical Systems 4(1984), 35- 52.

[6] R. L. Devaney, D.M. Look and D. Umnisky, "The Escape Trichotomy for Singular perturbed Rational maps", Indiana Univ. Mathematics Journal 54(2005), 267-285.

[7] R. L. Devaney and X. Jarque, "Indecomposable Continua in Exponential Dynamics", Conformal Geom. Dynamical 6(2002), 1-12.
[8] U. G. Gujar and V. C. Bhavsar, Fractals from $z \leftarrow z^{\alpha}+c$ in the Complex c-Plane, Computers and Graphics 15, 3 (1991), 441-449.

[9] U. G. Gujar, V. C. Bhavsar and N. Vangala, Fractals from $z \leftarrow z^{\alpha}+c$ in the Complex z-Plane, Computers and Graphics 16, 1 (1992), 45-49.

[10] E. F. Glynn, The Evolution of the Gingerbread Man, Computers and Graphics 15,4 (1991), 579-582.

[11] S. Ishikawa, "Fixed points by a new iteration method", Proc. Amer. Math. Soc.44 (1974), 147-150.

[12] G. Julia, "Sur 1' iteration des functions rationnelles", J Math Pure Appli. 8 (1918), 737-747

[13] B. B. Mandelbrot, The Fractal Geometry of Nature, W. H. Freeman, New York, 1983.

[14] Eike Lau and Dierk Schleicher, "Symmetries of fractals revisited.", Math. Intelligencer (18)(1)(1996), 45-51. MR1381579 Zbl 0847.30018.

[15] J. Milnor, "Dynamics in one complex variable; Introductory lectures", Vieweg (1999).

[16] Shizuo Nakane, and Dierk Schleicher, "Non-local connectivity of the tricorn and multicorns", Dynamical systems and chaos (1) (Hachioji, 1994), 200-203, World Sci. Publ., River Edge, NJ, 1995. MR1479931.

[17] Shizuo Nakane, and Dierk Schleicher, "On multicorns and unicorns: I. Antiholomorphic dynamics. hyperbolic components and real cubic polynomials", Internat. J. Bifur. Chaos Appl. Sci. Engrg, (13)(10)(2003), 2825-2844. MR2020986.

[18] Ashish Negi, "Generation of Fractals and Applications", Thesis, Gurukul Kangri Vishwvidyalaya, (2005).

[19] M.O.Osilike, "Stability results for Ishikawa fixed point iteration procedure", Indian Journal of Pure and Appl. Math., 26(1995), 937-945.

[20] A. G. D. Philip: "Wrapped midgets in the Mandelbrot set", Computer and Graphics 18 (1994), no. 2, 239-248.

[21] H. Peitgen and P. H. Richter, "The Beauty of Fractals", Springer-Verlag, Berlin, 1986.

[22] B. E. Rhoades, "Fixed point iterations for certain nonlinear mappings", J. Math. Anal. 183 (1994), 118-120.

[23] Rajeshri Rana, Yashwant S Chauhan and Ashish Negi. Article: Non Linear Dynamics of Ishikawa Iteration. International Journal of Computer Applications 7(13):4349, October 2010. Published By Foundation of Computer Science.ISBN: 978-93-80746-97-5

[24] M.Romera, G. Pastor and F. Montoya, "On the cusp and the tip of a midget in the Mandelbrot set antenna", Phys. Lett. A 221 (1996), no 3-4, 158-162. MR1409563 (97d: 58073).

[25] K. W. Shirriff, "An investigation of fractals generated by $z \rightarrow z^{-n}+c "$, Computers and Graphics 13, 4(1993), 603-607.

[26] R. Winters, "Bifurcations in families of Antiholomorphic and biquadratic maps", Thesis, Boston Univ. (1990).

[27] Yashwant S Chauhan, Rajeshri Rana and Ashish Negi. Article: New Julia Sets of Ishikawa Iterates. International Journal of Computer Applications 7(13):34-42, October 2010. Published By Foundation of Computer Science. ISBN: 978-93-80746-97-5 